\title{
A CULTURA SINO-PORTUGUESA NO SÉCULO XIX E O TA-SSI-YANG-KUO
}

Hélder Garmes

Universidade de São Paulo

$\mathrm{S}$

e durante os séculos XVI, XVII e XVIII a imprensa esteve presente em

Macau por conta dos jesuítas ou outras ordens religiosas, no início do século XIX não havia ali qualquer máquina impressora. Foi a revolução de 1820 que propiciou a reinstalação da imprensa em Macau e o início da publicação de periódicos.

É importante lembrar que, apesar da constante presença portuguesa desde o século XVI, a comunidade macaense sempre foi composta por uma grande maioria chinesa que mantinha vínculos pouco consistentes com os portugueses. A comunidade portuguesa vivia uma situação similar à de Goa, fechada em uma elite político-administrativa. Porém, em Macau, devido ao pagamento de tributos ao imperador chinês e às relações diplomáticas bastante instáveis, os mandarins tinham uma presença mais forte junto à elite portuguesa. Em Goa a elite portuguesa tinha maior autonomia.

O habitante chinês tinha geralmente origem em Cantão, província chinesa na qual Macau encontra-se situada. Dentro desse contexto, a cultura e a língua portuguesas estiveram sempre em luta cerrada e constante com a cultura e língua locais. O resultado foi sempre o de poucos chineses comunicarem-se em português e poucos portugueses, em chinês. Além disso, constituiu-se ali um crioulo português, o chamado patoá, que vinha distinguir o indivíduo macaense quer dos chineses, quer dos portugueses.

Numa situação tão delicada, a imprensa de língua portuguesa teve no decorrer do século XIX um papel muito importante na afirmação da identidade macaense e lusitana naquela península. 
De acordo com Manuel Teixeira, ${ }^{1}$ a imprensa macaense do século XIX apresentou dois períodos: 1822-1845 e 1863 até o final do século, separados por dezoito anos de profundo silêncio.

No primeiro, a literatura e a reflexão histórica sobre Macau apareceram timidamente nos vários periódicos políticos, sendo apenas no segundo, a partir de 1863, com o surgimento da revista Ta-ssi-yang-kuo, que tais matérias ganharam maior expressão nas publicações macaenses.

Entre os títulos do primeiro período, podemos citar a Gazeta de Macao (1824-1826), a Abelha da China (1822-1823), O Macaista Imparcial (18361838), o Boletim Official do Governo de Macau, ${ }^{2}$ (iniciado em 1838); A Gazeta de Macao (semanário homônimo ao de 1824, era na verdade o Boletim Official do Governo de Macau, que mudara de título); O Portuguez na China (1839-1843), A Aurora Macaense (1843³-1845); o Solitario na China (18441845) e O Procurador dos Macaistas (1844 -1845).

Em tais publicações evidencia-se o quanto a literatura jamais angariou grande prestígio entre os agentes desse jornalismo. Com os interesses voltados para a notícia corriqueira e para os acontecimentos políticos, os editores pouco ou nenhum espaço reservam para a - na Europa - tão valorizada ilustração. Mesmo a seção de variedades, muito em voga nos jornais metropoli-

TEIXEIRA (1965).

2 Quando Macau publica seu Boletim Official, Goa já possuía seu Boletim do Governo do Estado da India (7 dez 1837 a 30 abr 1880). De grande importância para o registro da história das colônias, devido à longa e ampla sobrevivência, os boletins das colônias foram instituídos em 7 de dezembro de 1836 por decreto do ministro Vieira de Castro, e efetivamente criados a partir do ano seguinte com boletim goês. Surgido em 1838, durou apenas até o ano seguinte e, sete anos após seu desaparecimento, ressurge como sob o título de Boletim do Governo da Província de Macau, Timor e Solor, assumindo posteriormente diversos outros nomes similares. Antônio Marques Pereira, que terá papel fundamental da história da imprensa em Macau, será seu redator entre março de 1860 e abril de 1862. A partir do exemplar de 6 de fevereiro de 1879 passa a ser publicado em português e chinês, por determinação do governandor Carlos Eugénio Correia da Silva.

3 A informação sobre esta publicação foi retirada de Manuel Teixeira (1965, p.34). Apesar de ali aparecer o ano de 1848 para o surgimento do periódico, isso não corresponde à ordem geral da obra de Teixeira, sendo o ano de 1843 - ou o de 1844 o que corresponde à seqüência ali seguida. Houve na certa erro tipográfico. 
tanos, onde a literatura e a ilustração sempre tiveram lugar cativo, era pouquíssimo cultivada nesse primeiro momento do jornalismo de Macau.

Faz-se notar, no entanto, o nome de Manuel Maria Dias Pegado como editor de vários periódicos, assim como o do poeta macaense José Baptista de Miranda e Lima ${ }^{4}$ (1782-1848), que compunha em português e em patuá num estilo ainda muito marcado pela literatura neoclássica, mas já incorporando alguns aspectos românticos.

Entre este primeiro e o segundo momento da imprensa macaense, abrese um parêntese de dezoito anos de ausência de publicações periódicas, à exceção do Boletim Official. Manuel Teixeira (1965) procurou a explicação para tal fenômeno tanto na fixação dos ingleses em Hong Kong, a partir de 1841, o que levou Macau à franca decadência econômica, como na repressão exercida pelo governo de Ferreira do Amaral, que governou Macau entre 21 de abril de 1846 e 22 agosto de 1849 - quando foi assassinado. A produção periódica macaense deslocou-se nesses anos para Hong Kong, quebrando em parte tal silêncio.

Para agravar a situação, a morte de Ferreira do Amaral, em 1849, foi seguida da publicação, em 1850, na metrópole, da "lei das rolhas", de Costa Cabral, que restringiu profundamente a liberdade de imprensa em toda a extensão territorial portuguesa.

Nesse momento, Macau começava a restabelecer-se economicamente devido à exportação de mão-de-obra semi-escrava dos cules, além da intensificação do comércio do ópio e da legalização das casas de jogo. Mesmo assim, a situação do porto de Macau em face ao de Hong Kong ainda era bastante desvantajosa e, em 1863, a cidade perdeu o direito de administração própria, conquistado em 1844, voltando a subordinar-se ao Estado da Índia (SILVA, 1994, p.12-27).

\section{O primeiro Ta-ssi-yang-kuo}

No mesmo ano em que perdeu sua autonomia provincial, veio reinaugurar a imprensa não oficial macaense o semanário históri-

Sobre Miranda e Lima há maiores informações num artigo que escrevi para a revista Leituras, da Biblioteca Nacional de Lisboa, n.2, 1998, p.209-230, intitulado "Poesia nas folhas de Macau: jornalismo e literatura”, artigo do qual em grande parte extraí esta comunicação. 
co e literário Ta-ssi-yang-kuo - Semanario macaense d'interesses publicos locaes, litterario e noticioso (1 jul. 1863 - 26 abr. 1866), tornando-se, apesar de sua curta duração, um dos hebdomadários oitocentistas mais prestigiados na história do século XIX de Macau. Foi fundado por José Gabriel Fernandes, natural de Siliom de Bardez, em Goa. ${ }^{5}$ Seu primeiro diretor foi Antônio Feliciano Marques Pereira, mas a edição efetiva ficava a cargo de José da Silva, sendo impresso na tipografia deste último.

O Ta-ssi-yang-kuo era um periódico liberal, católico, de caráter informativo, apresentando novas do reino, notícias locais, comerciais e portuárias, além de uma seção de anúncios. Mas, para além do caráter ideológicocristão e do perfil informativo, seus redatores tinham por intenção expressa ilustrar o leitor. No texto "Macau 7 de outubro" afirmava-se que:

É, pois, com intuito civilisador que damos a lume o nosso jornal (...) O nosso intuito é offerecer aos nossos leitores o conhecimento das coisas uteis, porque é esse o dever do escriptor serio e moralisado. ${ }^{6}$

E procurava-se cumprir o prometido, naturalmente dentro das limitações que então se colocavam no horizonte intelectual macaense. Além de Antônio Feliciano Marques Pereira, o periódico teve por colaboradores Alexandre Meireles de Távora, Gregório José Ribeiro, Cônego Antônio Maria Augusto de Vasconcelos, Jerônimo Osório de Castro Cabral Albuquerque, Manuel de Castro Sampaio, José Gabriel Fernandes, Pereira Rodrigues e José Pedro da Silva Campos Oliveira.

Antônio Feliciano Marques Pereira esclareceu, num artigo homônimo ao título do periódico, que Ta-ssi-yang-kuo significava "grande reino do mar do Oeste”, e que se referia ao reino português - tendo sido a expressão chinesa empregada pelo jesuíta Mateus Ricci quando, em 1600, em sua primeira audiência com o imperador Chin-tsung-hien-ti, foi perguntado de onde viera.

5 José Gabriel Fernandes (1816-1883) colaborou também no Jornal de Lisboa, no Paiz e no Tribuno Popular de Coimbra. Foi o pai de José Gabriel Bernardo Fernandes (1850-?), jornalista e historiador, autor dos Apontamentos para a historia de Macau (Lisboa, 1883), da Relação dos bispos de Macau (1884), e de O jornalismo em Macau, tendo colaborado no Jornal de Coimbra, no Conimbricense e no Impulso ás Letras de Hong Kong.

6 "Macau 7 de outubro", Ta-ssi-yang-kuo, 1863, 8 out., n.1, p.1. 
Faziam fé na retomada das missões católicas no Oriente. Parece que rezavam pela mesma cartilha que os militares dos Annaes Marítimos e Coloniaes (Lisboa, 1840-1846), que pretendiam revitalizar o modelo prépombalino da presença colonial portuguesa e, portanto, uma espécie de revisão e revitalização do modelo jesuíta de intervenção junto à comunidade chinesa. Lembremos que o pai de Antônio Feliciano Marques Pereira, que se chamava Feliciano Antônio Marques Pereira, era homem de letras e já fora sócio da Associação Marítima Colonial, que publicara os referidos Annaes.

Politicamente, o Ta-ssi-yang-kuo era tomado pela oposição como uma publicação para-oficial (e assim era, de fato), já que tinha fortes vínculos com o então governador José Rodrigues Coelho do Amaral (1863-1866), a ponto da existência do periódico coincidir exatamente com o período de administração do governador. ${ }^{7}$

\section{Ilustração e prosa literária}

No periódico aparecia por vezes uma "Secção Litteraria", em grande parte a cargo de Marques Pereira, ${ }^{8}$ que trazia as mais diversas matérias, tais como notícias históricas sobre a China, sobre as missões portuguesas no Oriente, sobre medicina, sobre geografia, botânica etc. O modelo dessa seção era certamente o jornalismo de ilustração da metrópole, como $O \mathrm{~Pa}$ norama ou da Revista Universal Lisbonense, isto é, o jornalismo de difusão de conhecimento útil e enciclopédico.

Mas seu interesse maior encontrava-se junto aos trabalhos historiográficos. O periódico publicou diversas matérias de relevo para a história de Macau, ressaltando-se a série de artigos "Bibliografia macaense", do próprio Antônio Feliciano Marques Pereira. Notemos que o interesse de Marques Pereira em relação à história de Macau não tinha origem no puro diletantismo intelectual, mas na intenção de legitimar os interesses políticos dos portugueses nas negociações com o governo chinês. Procurava-se criar uma funda-

Cf. Jorge Manuel dos Santos Alves (1995a, p.6).

$8 \quad$ Segundo afirma Jorge Manuel dos Santos Alves (1995a, p. 6). 
mentação documental e histórica para legitimar a posse de Macau por parte dos portugueses e se possível fazer de Macau o único entreposto comercial legítimo entre China e Europa, na busca de desqualificar a concorrência inglesa em Hong Kong. ${ }^{9}$

Ainda no âmbito da ilustração, foram publicados artigos sobre a educação relacionada à mulher, ao ensino do latim e à instruçóo pública, uma seção intitulada "Folhetim-Correspondencia", assinada por Z., e alguns textos relativos à história, tais como o relato da viagem a Hong Kong que fez M. C. S. ou o "Elogio historico do sr. Antonio José de Miranda, que a profunda saudade, e a notoriedade de seus feitos e acções fazem vir dos bicos da grosseira penna d'aquelle que se honra ser um dos seus numerosos amigos”, escrito por “G.”. O mais interessante de todos esses textos é sem dúvida os "Apontamentos sobre os cinco enforcados em Hongkong no dia 8 d'Agosto de 1865, pelo crime de piratas e assassinos, porém affirmando até ao patibulo a sua innocencia por quem lhes assistiu nas ultimas 12 horas de vida”. O texto apareceu em português e em inglês e tinha evidentemente maior sabor literário do que interesse histórico.

No gênero epistolar, apareceram seis cartas de Rigogero Soje Ibirore, "Recordação de viagens - Cartas a J. M. P. Rodrigues" e outras assinadas por Pancha e designadas "Cartas de Siára Pancha a Nhim Miquéla”, em crioulo macaense.

Quanto às narrativas em folhetim, estampou-se o texto "Confidencias de Mlle. Mars” (com tradução de Antônio Feliciano Marques Pereira), com indicação em nota de ter sido publicado por mad. Roger de Beavoir, e também “Tefine a bordo de um vapor: aventuras de John Drunkard - litterato espirituoso de um jornal inglez", notando ser uma tradução livre "sem pedir venia".

\section{A poesia}

Além dos textos em versos referentes a charadas, enigmas, acrósticos e logogrifos, o Ta-ssi-yang-kuo publicava grande diversidade de poemas. Pri-

$9 \quad$ Cf. Jorge Manuel dos Santos Alves (1995a, p.8-9). 
meiramente, veio à luz um texto assinado simplesmente por "V." sobre "O poeta”, que já nos forneceu um quadro teórico geral da produção que se seguiria, ao observar que "é o poeta quem verdadeiramente sente a natureza, por isso que vae pintal-a com todos os seus encantos, adornal-a com todas as suas galas"; concepção que ainda considerava o poeta como um imitador da natureza, ainda que uma imitação já romanticamente modulada por sua subjetividade. Quanto ao papel social do poeta, fazia notar que:

[...] [a voz do poeta] fazes com que a sociedade submissa e respeitosa va ajoelhar perante um nome, que talvez detestava; cravas o punhal no coração do tyranno, que faz a desgraça do seu povo e ri das miserias delle; ensinas-nos a olhar a morte como um bem, quando trocada a vida pela patria; espalhas por entre todos o germen fecundante da virtude, que exaltas com teus cantos, germen, que, pousando ocioso e tranquillo sobre o coração, lá fica até que uma occasião propicia venha fazel-o brotar cheio de viço $[\ldots]^{10}$

Prestigiado, eventualmente marginal, justiceiro, patriota e acima de tudo semeador da virtude, a definição ali presente parecia referir-se tanto ao modelo do poeta clássico (virtuoso e exemplar, patriota) como ao do poeta romântico (genial, marginal, justiceiro, patriota). E para colocar em prática tal definição, apareceram diversos trabalhos poéticos. De Manuel de Castro Sampaio tivemos: duas quadras sem título, a "Poesia aos annos da Exma. Sra. Guilhermina da Rocha Assumpção", uma "Elegia”, um "Epicedio á prematura morte do Illmo. Sr. Major José Roberto" e os versos "Uma lagrima”. De Gregório José Ribeiro, o poema "Canto sentido". De alguém que assinava apenas S., apareceu "O mendigo", e completamente anônimos havia "Um trahido" e "N'um album de uma senhora de Macau - O Album e eu”. De José Pedro da Silva Campos Oliveira publicou-se "Amo-te”, poema que já havia sido publicado na Illustração Goana.

É interessante notar que, junto ao poema de Campos Oliveira, veio a seguinte observação:

10 V., “O poeta”, Ta-ssi-yang-kuo, 1864, 21 jan., n.16, p.64. 
Com muito gosto publicamos uma poesia, que nos foi enviada pelo seu auctor o sr. Campos e Oliveira, talentoso jovem de 17 annos, que começa a cultivar as letras de um modo muito promettedor.

Traz a data de: “Margão, 15 de fevereiro de 1865”. José Pedro da Silva Campos e Oliveira era moçambicano, mas encontrava-se naquele momento em Goa, onde colaborava sistematicamente na Illustração Goana e onde tinha editado o Almanach popular para os anos de 1864, 1865 e 1866. Será o mais prestigiado poeta moçambicano do século XIX, fundando em Moçambique, em 1881, a primeira revista literária daquela colônia, a Revista Africana.

Outro que aí se destacava pelo volume de trabalhos publicados era Manuel de Castro Sampaio. Fora enviado para o Oriente como capitão na guarnição de Macau e Timor. Sócio-correspondente da Real Sociedade Asiática de Londres, além de colaborar no Ta-ssi-yang-kuo, publicou: Pobreza envergonhada (Valença, 1852); uma tradução livre do texto de D. Francisco Tamires Vaz, Compendio de hygiene popular (Elvas, 1860); Victimas de uma paixão (Lisboa, 1863); Memorias dos festejos realisados em Macau no fausto nascimento de S. A. o sr. D. Carlos Fernando (Macau, 1864); Compendio de ortographia (Macau, 1864); Os chinas em Macau (Hong Kong, 1867); além de relatórios oficiais e outros dois poemas publicados no Boletim do Governo de Macau: "Elegia á prematura morte da Exma. Sra. D. Camilla de Mello..." e "Nenia á infausta e sentida morte do Illmo. Sr. José Bernardo Goularte...”.

\section{Avaliação geral das matérias literárias publicadas}

Como se pode constatar, o Ta-ssi-yang-kuo trouxe um novo alento para o cultivo da literatura e da ilustração em Macau. Vale notar que as narrativas aqui publicadas caracterizam-se pelo seu vínculo com a verossimilhança. Dá-se preferência a relatos de viagens, cartas, elogios históricos, confidências, casos sensacionalistas, enfim, a todo gênero de narrativa que simule, ou efetivamente tenha, um 
vínculo com a realidade. A literatura romântica de verve fantástica, imaginosa, não teve lugar.

Isso pode ser interpretado como indício do baixo grau de formação letrada do público macaense, que domina pouco as convenções literárias para chegar a apreciar narrativas que fujam a uma referência de realidade mais imediata. Também pode apontar para uma resistência neoclássica à fantasia romântica, resistência que já se encontrava presente em Miranda e Lima, o mais prestigiado poeta macaense do século XIX. Como última, mas certamente mais provável hipótese, trata-se de uma questão eminentemente cultural resultante do conflito cultural criado entre Ocidente e Oriente, isto é, o vínculo com a realidade é valorizado porque se busca construir literariamente o exotismo oriental. A descrição subjetiva de viagens ou mesmo a descrição "realista", assim como o próprio texto histórico, exercitam o olhar do Ocidente sobre o Oriente no sentido de carregar este último de significações pré-concebidas, sejam elas positivas ou negativas, desenvolvidas desde os primeiros contatos entre os europeus e as regiões do Oriente (cf. SAID, 1996, p. 41-119).

No âmbito da poesia publicada no Ta-ssi-yang-kuo a marca romântica se faz sentir de modo mais contundente, ainda que de forma contida para os parâmetros europeus, rejeitando da mesma forma o ultra-romantismo fantasioso.

Tais elementos apontam para um conservadorismo formal que, de fato, caracterizará toda a literatura macaense do século XIX. No que diz respeito aos artigos de ilustração, que contemplavam temas históricos, geográficos, culturais, também não há qualquer aspecto polêmico, procurando-se sempre reafirmar a importância da presença portuguesa no Oriente e caracterizar o exotismo cultural do chinês.

Assim, podemos concluir que o primeiro Ta-ssi-yang-kuo veio fazer renascer as publicações periódicas em Macau, após o silêncio de dezoito anos, dentro de um espírito patriótico, cristão, esteticamente moderado, que, se por um lado somente reforçava a visão européia do chinês, por outro inaugurava um certo gênero de jornalismo ilustrado até então desconhecido por aquela comunidade, gênero que remontava em parte, no que diz respeito ao aspecto de formação literária e cultural da publicação, ao modelo do Panorama (1836-1867) de Alexandre Herculano, como já observamos. 


\section{Antônio Feliciano Marques Pereira}

É necessário relevar aqui a figura de Antônio Feliciano Marques Pereira, homem que muito contribuiu para o desenvolvimento do meio literário de Macau. Apesar de ser lisboeta por nascimento (em 1839), residiu em Macau desde os vinte anos, uma vez que sua família ali se estabelecera.

Ainda em Lisboa, colaborou com diversos periódicos, como Rei e Ordem, Archivo Pittoresco, Revista dos Espectaculos, Revista de Lisboa, Arquivo Familiar e Ilustração Luso-Brasileira, entre outros. No Rei e Ordem, publicou os Romances originaes, onde constavam os seus seguintes folhetins: "Ciúme de poeta"; "Ciúme de uma mulher do grande mundo"; "Romance de uma pecadora" (transcrito no Archivo Familiar); "Uma reconciliação" (que já fora publicado na Illustração Luso-Brasileira); "Amor e reflexão" (incompleto). Ainda no Rei e Ordem, publicou sua tradução das Confidências de mlle. Mars, por mad. Roger de Beauvoir, que aparece também no Tassi-yang-kuo, além de algumas biografias de Mirecourt.

Mas um de seus trabalhos teve uma história à parte. Ainda em Lisboa, em 1858, publicou Uma mulher do seculo, romance contemporaneo, precedido de um juizo critico de Francisco Maria Bordalo (que fora um dos fundadores de $O$ Panorama). Inocêncio relatou que:

Pouco depois de sua chegada a Macau, o auctor vendo a procura que ahi tinha a sua obra, a primeira que até então houvesse publicado, escreveu em 7 de Abril de 1860 no Boletim do Governo (cujo redactor começou a ser desde 20 de Março de antecedente) um extenso artigo, intitulado Duas palavras a respeito de um livro, em que, sem renegar a paternidade da sua producção, rejeitava contudo a indole della n'alguns pontos, e pedia que sob esse aspecto, e bem assim debaixo do ponto de vista litterario, a Mulher do seculo fosse apenas considerada como estrêa arrojada dos seus dezenove annos (SILVA, t. VIII, p. 139).

Assim, parece que por conveniência política Antônio Feliciano Marques Pereira se curvou rapidamente ao conservadorismo moral e literário macaense. Ali foi redator do Boletim do Governo, de 20 de março de 1860 a abril de 1862, sendo que seu prestígio literário local teve início, de fato, com 
seus Esboços e perfis, colecção de romances e estudos sociais (1862), tendo sedimentado-se na direção do Ta-ssi-yang-kuo (1863-1866). Ainda publicou as Ephemeredes commemorativas da historia de Macau (1868) e $O$ padroado português na China (1873) - uma de suas mais conhecidas obras -, além de outros trabalhos sobre administração pública.

Em 1869, Antônio Feliciano Marques Pereira seria acusado por António José da Silva e Sousa, então redator do periódico O Echo do Povo, de Hong Kong, de práticas de corrupção em suas atividades como magistrado em Macau, acabando, no entanto, por ganhar a causa contra o acusador. Pela documentação apresentada pelo padre Manuel Teixeira (1965: 268-269), tudo indica que o redator de $O$ Echo do Povo estava com a verdade. Mas, como sabemos, Manuel Teixeira não se pauta pela imparcialidade em seus julgamentos - sempre em defesa dos jesuítas e da ala conservadora da Igreja. $\mathrm{O}$ fato é que, mesmo saindo vencedor, Antônio Feliciano Marques Pereira acabou sendo substituído pelo bacharel em direito Júlio Ferreira Pinto Basto. Lembremos, entretanto, que $O$ Echo do Povo era financiado por Bernardino de Senna Fernandes, que ocupava o cargo de superintendente da imigração, num momento em que a "imigração dos cules" - eufemismo para a escravização desse grupo étnico - era o grande negócio de Macau. É possível que Antônio Feliciano Marques Pereira, por ser magistrado e por suas posições políticas, representasse algum entrave nesse processo "migratório", o que teria motivado a acusação do periódico de Senna Fernandes.

$\mathrm{O}$ fato é que, em seguida a esse episódio, Marques Pereira abandonou a cidade de Macau e depois de algum tempo passou a exercer a função de cônsul de Portugal no Sião, hoje Tailândia, entre 1875 e 1881, ano em que morreu.

Antônio Feliciano Marques Pereira participou ativamente daquele que seria, segundo José Vicente Serrão (1998, p.722), um dos problemas centrais do século XIX em Macau: a afirmação da soberania portuguesa sobre o território, uma vez que a situação jurídica de Macau nunca ficara devidamente definida junto às autoridades chinesas. No entanto, Marques Pereira deixou Macau sem ter conseguido definir tal soberania, mas produziu uma consistente historiografia que fundamentou a atividade de seu filho anos depois em Lisboa. 


\section{O segundo Ta-ssi-yang-kuo}

O segundo Ta-ssi-yang-kuo, subintitulado Archivos e annaes do Extremo-Oriente português. Colligidos, coordenados e annotados por J. F. Marques Pereira 1. Official, chefe de secção, do Ministerio da Marinha e Ultramar; Official da Ordem de S. Thiago, do merito scientifico, litterario (18891904?), ${ }^{11}$ foi editado em Lisboa por João Feliciano Marques Pereira (18631909), filho de Antônio Feliciano Marques Pereira, que pretendeu dar continuidade aos trabalhos paternos sobre a história de Macau. No texto introdutório da publicação afirmou que:

A revista tem por titulo Ta-ssi-yang-kuó (cuja razão o leitor encontrará mais adeante) [no atual trabalho tal tradução e explicação já foi dada] e o sub-titulo Archivos e Annaes do Extremo-Oriente Portuguez e constituirá uma especie de repositorio de documentos antigos, ineditos ou não, relativos á expansão portugueza n'essa parte do mundo, e bem assim de estudos, monographias, apontamentos, sobre a historia, civilisação, ethnographia, philologia, linguistica, folk-lore, usos e costumes de todos esses povos que estiveram ou estão em contacto com os portuguezes, como, por exemplo, os chins, os malaios, os siamezes, os japonezes, etc.; constituindo, por assim dizer, um archivo de noticias ou de dados curiosos que ou estão espalhados por diversas obras, algumas raras e difficeis de adquirir, ou por manuscriptos, a maior parte ineditos, das bibliothecas e archivos nacionaes. E, quando fôr opportuno, e se tiverem estabelecido relações entre esta revista e os actuaes centros da vida portugueza no Extremo-Oriente, haverá uma resenha de todo o movimento actual d'esses nucleos de portuguezes ou de descendentes de portuguezes que existem ainda em Macau, Hong Kong, Timor, Malaca, Singapura, Siam, Manila, e em certos portos da China e do Japão. Emfim, será uma especie d'essas revistas ou Archivos publicados na India por Cunha Rivara, Nery Xavier, etc., mas elaborado sob um ponto de vista mais moderno e abrangendo todas as manifestações da vida, quer pas-

\footnotetext{
11 O ano do término da publicação foi inferida a partir da referência temporal mais tardia presente na publicação.
} 
sada, quer presente, d'esses povos, nas suas relações comnosco, e a influencia reciproca que d'elles recebemos ou que sobre elles exercemos por intermedio dos nossos benemeritos missionarios, soldados, marinheiros e commerciantes. E, para amenisar (condição essencial a toda a publicação, que pretenda ser bem acceita pelo publico), será acompanhada de gravuras, vistas, estampas, representando monumentos, retratos, plantas de cidades, povoações e fortalezas, fac-similes de documentos raros, productos da fauna e flora; usos e costumes, etc. Emfim todos os attractivos d'uma publicação moderna e que constitua no genero uma novidade entre nós. ${ }^{12}$

Era editado na Companhia Nacional Editora, com a colaboração de distintos historiadores das regiões coloniais. ${ }^{13}$ Não era uma publicação macaense, no sentido estrito do termo, já que era editada em Lisboa.

Sua concepção se filia explicitamente à tradição de revistas históricas luso-chineses, que teve origem em Goa, com Cunha Rivara e Nery Xavier, remontando, obviamente, ao modelo de O Panorama (1837-1868), editado primeiramente por Alexandre Herculano, no qual Cunha Rivara também colaborou, tomando já em Goa o trabalho de Herculano como modelo a ser seguido.

Guardadas as distinções no que concerne aos recursos técnicos então disponíveis - como reproduções fac-símiles de documentos, fotografias etc. , temos no segundo Ta-ssi-yang-kuo a concretização (em grande estilo e qualidade) do modelo da revista enciclopédica oitocentista instituída em Portugal por Alexandre Herculano, modelo aqui voltado exclusivamente para os interesses do Oriente português e que teve na produção periódica goesa - e isso é importante - sua referência mais próxima. Eis, nesse caso, o delineamento de uma rota literária que saía de Portugal para Goa, chegava a Macau e retornava para Lisboa. Não devemos esquecer que o dono do primeiro Ta-ssiyang-kuo era uma goês.

\footnotetext{
12 João Feliciano Marques Pereira, “Razão da tentativa”, Ta-ssi-yang-kuo, 1899-1900, v.I-II, p.12-13.

13 Entre eles, Sebastião Rodolfo Salgado e Antônio de Campos Junior.
} 
O primeiro e o segundo Ta-ssi-yang-kuo fornecem também o indício da progressiva importância que os estudos si o-portugueses ganharam aos olhos da metrópole. Isso possivelmente se relacionava com o grande interesse suscitado pela voga de "orientalismo" que tomou toda a Europa do final do século.

Sua coleção é uma fonte ímpar de estudos oitocentistas sino-portugueses. ${ }^{14}$ Apenas para se ter idéia do interesse dessa publicação, lembremos, somente para citar alguns trabalhos que interessam diretamente à literatura e às artes, que foi ali publicado um "Cancioneiro musical creoulo", as "Reminiscencias peninsulares nas Molucas - Canções populares de Amboina e Ternate”, as “Chinezices... Notas para os 'barbaros' occidentaes - I. Jantares e comezainas", o "Folk-lore macaista", os "Costumes e crenças da China", de Callado Crespo, "Uma resurreição historica (Paginas inéditas d'um visitador dos jesuitas) (1665-1671)”, o "Diu (Excerptos d’um livro inédito)”, de A. Pereira Nunes, o texto "Em prol de umas ruinas (A proposito do frontespicio do Collegio de S. Paulo, em Macau)”, alguns “Trechos da descripção de Pekim por Fernão Mendes Pinto", entre diversos outros.

Como podemos observar apenas pelos títulos acima, a revista editava não só matérias sobre Macau, mas também muitos trabalhos sobre Goa, uma vez que ambas as localidades eram entendidas como colônias do Oriente. Isso é significativo, pois o Ta-ssi-yang-kuo vem legitimar e divulgar não só o trabalho de Antônio Feliciano Marques Pereira e seus colaboradores em Macau mas também o trabalho do grupo que se formara a partir da atuação de Cunha Rivara em Goa.

É, portanto, a iniciativa de João Feliciano Marques Pereira e de seus colaboradores que possibilita uma revalorização do trabalho histórico e literário realizado em meados do século XIX por iniciativa de alguns portugueses no Oriente. Lembremos que João Feliciano era macaense de nascimento, tendo estudado num colégio luso-britânico e cursado Letras em Lisboa. Tornou-se funcionário do Ministério da Marinha e do Ultramar e atuou

14 Neste trabalho, utilizou-se sempre a edição fac-símile da Fundação Macau, editada em 1995, em dois volumes: o primeiro tomo correspondendo aos volumes I-II, e o segundo aos volumes IIIIV. As referências aqui presentes a tais publicações são feitas a partir dessa edição. 
como um especialista em questões que envolviam as relações luso-chinesas, chegando a representar o círculo eleitoral de Macau em 1908 e 1909.

Assim, como seu pai, esteve sempre envolvido nas relações diplomáticas entre Portugal e China. A questão política em torno da convenção de Pequim em 1902, negociada entre José de Azevedo Castelo Branco e o mandarim Yikuang foi um dos tópicos que, ao lado de questões culturais e literárias, preencheram as páginas do Ta-ssi-yang-kuo, revelando aqui a forte oposição de João Feliciano às negociações encaminhadas por Castelo Branco, o que atribui um forte viés político a uma publicação que se apresentava como eminentemente cultural. ${ }^{15}$

O fato é que Antônio Feliciano Marques Pereira e seu filho João Feliciano, juntamente com aqueles que os cercavam, foram os grandes responsáveis pelo trabalho historiográfico em torno de Macau. Cumpriram o papel que Herculano fizera em Portugal, ou que Cunha Rivara e seus discípulos em Goa, divulgando na metrópole portuguesa documentos e estudos sobre tais localidades até então pouquíssimos conhecidos e construindo um discurso sobre a colonização portuguesa no Oriente que se encontrava até então pouco conhecida.

Se observarmos com atenção, houve um esforço dos seguidores de Alexandre Herculano em fazer com as colônias do Oriente, no âmbito do jornalismo de ilustração e da historiografia, o que o editor de $O$ Panorama e o autor da História de Portugal fizera em relação à nação lusitana.

Havia uma concepção de conhecimento em tais empreendimentos que relacionava a investigação da verdade (no caso a "verdade histórica") com a sua divulgação em grande escala de tal investigação através da imprensa. Esse jornalismo de ilustração, que teve em última instância o intuito de civilizar seus leitores, fez parte do projeto do romantismo português fundamentado por Herculano.

Será com o primeiro Ta-ssi-yang-kuo que se inaugurará a fase dessa imprensa ilustrada e civilizadora em Macau, que redundará num grande número de publicações, como o Almanach luso-chinez de Macau (1866), O Independente - Jornal politico e noticioso (ago. 1868 - 24 jul. 1898?), O Noticiário Macaense (11 jan. 1869 - 24 fev. 1870), Gazeta de Macau e Timor - Semanario 
politico, litterario e noticioso (20 set. 1872 - 20 mar. 1874), O Oriente (10 out. 1869 - 21 jan. 1879), O Imparcial (5 abr. 1873 - ?), O Jornal de Macau Politico, litterario e noticioso (1 abr. 1875 - 8 mar. 1876), O Macaense (28 fev. 1882 - 28 out. 1886), O Correio de Macau - Semanario politico, litterario e de noticias (15 out. 1882 - 5 ago. 1883), O Correio Macaense - Semanario politico, litterario e de noticia (2 set. 1883 - dez. 1889?), A Voz do Crente (1ㅇ jan. 1887 - 29 dez. 1894), A Liberdade - Semanario politico, noticioso e litterario (19 jul 1890? - ?), O Macaense - Jornal politico, litterario e noticioso (1891), O Oriente Portuguez - Semanario dedicado aos interesses portuguezes da China e Oceania (20 abr. 1892 - 1893 ou 1894?), Echo Macaense - Semanario Luso-Chinez (jul. 1893 - 24 set. 1899), O Lusitano (28 ago. 1898 - dez. 1899).

Algumas dessas publicações tinham um perfil eminentemente político e noticioso, porém já não era estranho aparecer matérias literárias ou de ilustração. É certo que, se comparadas com as publicações portuguesas, as macaenses deixam muito a desejar no aspecto literário e ilustrativo. Todavia, pela própria quantidade de títulos fica evidente um certo dinamismo intelectual, ainda que pautado fundamentalmente por questões políticas imediatas. E vale lembrar que nessa relação não está incluído o jornalismo em língua portuguesa praticado em Hong Kong, Xangai e Cantão, redutos de opositores ao governo de Macau, que também chegaram a apresentar publicações eminentemente literárias, como, por exemplo, o periódico O Impulso ás Letras (1o out. 1865 - 1ำ set. 1866) de Hong Kong.

O curioso é que tal projeto de cunho romântico só ganha legitimidade no final do século XIX e início do XX, com a importação da reflexão local de Macau e Goa para o segundo Ta-ssi-yang-kuo, editado em Lisboa. É a produção colonial que alimenta a publicação da metrópole, num momento em que a idéia de civilização era profundamente questionada por escritores como Eça de Queirós, Antero de Quental e, já de uma outra perspectiva, por Camilo Pessanha, que passa a residir em Macau exatamente nesse período.

\section{Observações finais}

Mesmo chegando tarde no que concerne à sensibilidade romântica, o esforço dos que trabalharam em torno dos dois Ta-ssi-yang-kuo cumpriu 
um importante papel para o projeto historiográfico rnmântico inaugurado por Herculano: integraram Macau e Goa (esta última a partir da legitimação na metrópole dos trabalhos desenvolvidos na Índia) ao referido projeto, atribuindo a tais localidades um passado razoavelmente documentado. Se isso não bastasse, vieram responder em Portugal à onda orientalista que então surgia na Europa no âmbito da literatura, do pensamento e das artes, que contribuía, segundo Edward Said (1996, p.41-119), com o qual concordamos, para um processo de orientalização do Oriente, no sentido de estigmatizar os povos da Ásia em função da dominação cultural e dos interesses econômicos europeus.

Literariamente, a produção local deixou a desejar, mas, assim como acontecera no século XVI com a passagem de Camões, e no século XVIII com a passagem de Bocage, Macau teve o privilégio de abrigar no final do XIX e início do XX outro dos maiores poetas de língua portuguesa, Camilo Pessanha. Este, poeta e sinólogo, em 1924, ao procurar legitimar a mítica em torno da gruta de Camões (gruta em Macau onde o poeta teria escrito parte de $O s$ Lusíadas), afirma que "ainda é Macau a única terra de todo o ultramar português em que se pode ter até certo ponto a ilusão de se estar em Portugal”.16 Tal ilusão não sobreviveu até nossos dias, já que a crescente globalização imprimiu a Macau o mesmo perfil de tantas outras grandes cidades do mundo, além do fim institucional da administração portuguesa em 2000.

Mas, após quase cinco séculos de precária administração, ficou para a memória portuguesa a afirmação de sua constante presença no Oriente e, portanto, a sua contribuição para os estudos orientais. E é por isso que o "grande reino do mar do Oeste", isto é, o Ta-ssi-yang-kuo, jamais será apagado da história portuguesa e da história da separação do mundo entre Ocidente e do Oriente.

Em resumo, perdida a perspectiva de uma presença econômica relevante na costa chinesa, os portugueses passaram a uma afirmação de sua presença cultural no Oriente, com a elaboração de uma história dessa presença, resultando no final do século XIX na reivindicação da autoridade de um discurso sobre o Oriente na edição do segundo Ta-ssi-yang-kuo. Na prá-

16 Em Pessanha (1993: 122). 
tica, partem de uma atuação econômica na China para uma atuação intelectual na Europa. Em ambos os casos, é a disputa pelo poder junto aos países europeus que sempre esteve em jogo. As relações sino-portuguesas tiveram como interlocutores os países europeus. Daí a necessidade de olharmos para o discurso português sobre a China no primeiro e no segundo Ta-ssi-yangkuo como um modo de Portugal afirmar seu direito frente ao discurso hegemônico do orientalismo ditado então pela Inglaterra e pela França.

\section{BIBLIOGRAFIA}

ALVES, Jorge Manuel dos Santos (pref.) Ta-ssi-yang-kuo, 1863-1866. Macau, Direcção dos Serviços de Educação e Juventude, Fundação Macau, 1995a.

. (pref.). Ta-ssi-yang-kuo,1899-1900. Macau, Direção dos Serviços de Educação e Juventude, Fundação Macau, 1995b.

AZEVEDO, Rafael Ávila de. A influência da cultura portuguesa em Macau. Lisboa, Instituto de Cultura e Língua Portuguesa, 1984.

MORAIS, Carlos Alexandre de Cronologia geral da Índia portuguesa. Macau, Instituto Cultural de Macau, Instituto Rainha D. Leonor, 1993.

PESSANHA, Camilo. China. 2.ed. Lisboa, Veja, 1993.

RODRIGUES, Ernesto José. Mágico folhetim: literatura e jornalismo em Portugal. Universidade de Lisboa (tese de doutorado em Cultura Portuguesa), 1996, 2 v.

SAID, Edward. Orientalismo - o Oriente como invenção do Ocidente. São Paulo, Companhia das Letras, 1996.

SERRÃO, José Vicente. “Macau”. In: Joel Serrão, A. H. de Oliveira Marques (dir.), Valetim Alexandre, Jill Dias (coord.) Nova história da expansão portuguesa - O império africano - 1825-1890. Lisboa, Editorial Estampa, v. X, 1998.

SILVA, Beatriz Basto da. A emigração dos cules. Dossier Macau 1851-1894. Macau, Fundação Oriente, 1994.

SILVA, Francisco Inocêncio da. Dicionário bibliográfico português. Lisboa, Imprensa Nacional, 1958, t. VIII, p. 139.

TEIXEIRA, Manuel. A imprensa periódica portuguesa no Extremo-Oriente. Macau, Notícias de Macau (Coleção Notícias de Macau, XXII), 1965. 